\title{
The formation of ice in a long-lived supercooled layer cloud
}

Article

Accepted Version

Westbrook, C. D. and Illingworth, A. J. (2013) The formation of ice in a long-lived supercooled layer cloud. Quarterly Journal of the Royal Meteorological Society, 139 (677). pp. 2209-2221. ISSN 1477-870X doi: https://doi.org/10.1002/qj.2096 Available at https://centaur.reading.ac.uk/32606/

It is advisable to refer to the publisher's version if you intend to cite from the work. See Guidance on citing.

Published version at: http://onlinelibrary.wiley.com/doi/10.1002/qj.2096/abstract

To link to this article DOI: http://dx.doi.org/10.1002/qj.2096

Publisher: Royal Meteorological Society

All outputs in CentAUR are protected by Intellectual Property Rights law, including copyright law. Copyright and IPR is retained by the creators or other copyright holders. Terms and conditions for use of this material are defined in the End User Agreement.

\section{www.reading.ac.uk/centaur}

\section{CentAUR}

Central Archive at the University of Reading

Reading's research outputs online 


\title{
The formation of ice in a long-lived supercooled layer cloud
}

\author{
C. D. Westbrook*, A. J. Illingworth \\ Department of Meteorology, University of Reading, UK \\ ${ }^{*}$ Correspondence to: Dr. Chris Westbrook, Dept of Meteorology, PO Box 243, Earley Gate, Reading, RG6 6BB, UK. \\ Email c.d.westbrook@ reading.ac.uk
}

\begin{abstract}
This paper focusses on the characteristics of persistent, thin single-layer mixed-phase clouds. We seek to answer two important questions: (i) how does ice continually nucleate and precipitate from these clouds, without the available ice nuclei becoming depleted? (ii) how do the supercooled liquid droplets persist in spite of the net flux of water vapour to the growing ice crystals? These questions are answered quantitatively using in-situ and radar observations of a long-lived mixed-phase cloud layer over the Chilbolton Observatory.

Doppler radar measurements show that the top $500 \mathrm{~m}$ of cloud (the top $250 \mathrm{~m}$ of which is mixed-phase, with ice virga beneath) is turbulent and well-mixed, and the liquid water content is adiabatic. This well mixed layer is bounded above and below by stable layers. This inhibits entrainment of fresh ice nuclei into the cloud layer, yet our in-situ and radar observations show that a steady flux of $\approx 100 \mathrm{~m}^{-2} \mathrm{~s}^{-1}$ ice crystals fell from the cloud out over the course of $\sim 1$ day. Comparing this flux to the concentration of conventional ice nuclei expected to be present within the well-mixed layer, we find that these nuclei would be depleted within less than $1 \mathrm{hr}$. We therefore argue that nucleation in these persistent supercooled clouds is strongly time-dependent in nature, with droplets freezing slowly over many hours, significantly longer than the few seconds residence-time of an ice nucleus counter. Once nucleated, the ice crystals are observed to grow primarily by vapour deposition, because of the low liquid water path $\left(21 \mathrm{gm}^{-2}\right)$, yet vapour-rich environment. Evidence for this comes from high differential reflectivity in the radar observations, and in-situ imaging of the crystals. The flux of vapour from liquid to ice is quantified from in-situ measurements, and we show that this modest flux $\left(3.3 \mathrm{gm}^{-2} \mathrm{hr}^{-1}\right)$ can be readily offset by slow radiative cooling of the layer to space. Copyright (c) 2012 Royal Meteorological Society
\end{abstract}

Key Words: ice nucleation; glaciation; stochastic; singular

Received...

Citation: ...

\section{Introduction}

Thin cloud layers containing supercooled water droplets are a frequent occurrence in the atmosphere (Hogan et al. 2003; Smith et al. 2009) and global observations by satellite-borne radar and lidar indicate that they account for approximately one-third of all mid-level clouds (Zhang et al. 2010). These clouds can be challenging for both numerical weather-prediction and cloud-resolving models to successfully simulate (Marsham et al. 2006), but have a significant role to play in the radiation budget of the earth (Hogan et al. 2004).

Of particular interest is the formation of ice in such clouds. Westbrook and Illingworth (2011) presented statistics from 4 years of continuous radar and lidar observations, and showed that in $95 \%$ of cases ice formation at temperatures $>-22^{\circ} \mathrm{C}$ occurred in supercooled clouds. Ansmann et al. (2009) analysed 1 month of lidar observations of tropical altocumulus clouds and found that liquid water was always detected first before the onset of ice fallstreaks. Similarly de Boer et al. (2011) found evidence that ice did not form without the presence of liquid droplets in arctic boundary layer clouds.

Rauber and Tokay (1991) and Shupe et al. (2011) noted the apparent abilty of these thin layer clouds to persist in a mixed-phase state for long periods of time. For example, Westbrook et al. (2010a) describe a 300m-deep supercooled layer in which ice crystals were formed continuously for 8 hours, and precipitated steadily from the base of the layer. The relatively simple microphysical structure of these thin layers, and their long lifetime, make them a natural laboratory for the study of ice formation and growth.

The observations cited above raise two important questions:

1. How does ice continually nucleate and precipitate from these clouds, without the available ice nuclei becoming depleted?

2. How do the supercooled liquid droplets persist in spite of the net flux of water vapour to the growing ice crystals?

In this paper we attempt to answer both of these questions quantitatively, using data from in-situ and radar 
observations collected in a persistent mixed-phase layer cloud which was present over the Chilbolton Observatory in the UK for $\sim 1$ day.

\subsection{Time-dependence and ice nucleation reviewed}

To set the scene for the arguments surrounding question 1, we offer this brief summary outlining the two strands of ideology which have been used to understand ice nucleation in supercooled clouds in the past. These two approaches, referred to as the 'singular' and 'stochastic' hypotheses have been formulated in detail by Vali and Stansbury (1966).

The stochastic hypothesis assumes that nucleation is a random process, and that each droplet in a supercooled cloud contains an identical ice nucleus (or distribution of nuclei). Droplets at a given temperature freeze at random, and with fixed probability per unit time $P$ at a given temperature $T$.

The singular hypothesis in contrast neglects any probabilistic element to the freezing process, and instead characterises it by a characteristic temperature $T_{c}$. Once a nucleus has been cooled to $T_{c}$, freezing occurs immediately. As a result, ice forms only during the cooling process, and not if $T$ is held constant.

Clearly these two hypotheses are limiting cases of the more general situation where freezing of individual nuclei is probabilistic, but where there is also a spectrum of different nuclei distributed among the droplets, each with their own $P(T)$ relationship. In this framework the singular approximation corresponds to the case where (i) $P(T)$ has a form approaching a step function centred on $T_{c}$, and (ii) there is a broad spectrum of nuclei with different $T_{c}$. Meanwhile the stochastic approximation corresponds to the case where (i) $P(T)$ is a continuous function of temperature, and (ii) all droplets contain nuclei with identical $P(T)$ (or identical distributions of nuclei with different $P(T)$ ). A more in depth discussion of these ideas is provided by Niedermeir et al. (2011).

More details of laboratory evidence supporting the singular and stochastic hypotheses are reviewed later in section 4 . However, there has been a relatively widespread acceptance in the community that ice nucleation is an approximately singular process, and time-dependence may be neglected. This assumption is particularly important for the measurement of available ice nuclei in-situ using continuous flow ice nucleus counters (eg. DeMott et al. 2010), since the residence time of a nucleus in such instruments is typically only a few seconds. However, the assumption of a singular mechanism seems difficult to reconcile with the observations of long-lived mixed-phase layer clouds with a constant cloud top temperature, since in the absence of a source of fresh ice nuclei, the ice particles should quickly be activated and depleted by precipitation (Fridlind et al. 2012), following which the cloud would become purely liquid. This does not occur in our case study, nor in other examples we have investigated (e.g. Westbrook et al. 2010a), and in section 4 we attempt to establish whether this could be explained by entrainment, or whether it is evidence that freezing is occurring over long time scales.

\subsection{Glaciation of mixed-phase clouds}

The problem addressed by question 2 is related to glaciation. Bergeron (1935), amonst others, recognised that the difference in saturation vapour pressure between liquid and ice surfaces at the same temperature leads to a flux of vapour from liquid to ice in a mixed-phase cloud, and in the absence of an external dynamical forcing this ultimately leads to complete evaporation of the liquid droplets, and the growth of ice crystals at their expense. 'Hole-punch' clouds are an extreme example of this process (Westbrook and Davies 2010).

Korolev and Isaac (2003) computed the glaciation time for a population of liquid and ice particles which were allowed to evolve freely within a self-contained air parcel. In the absence of any forcing, complete glaciation was found to occur on timescales of order $\sim 1 \mathrm{hr}$. This appears to be at odds with the observation that supercooled clouds can persist for many hours or even days. Korolev and Isaac (2003) and Korolev and Field (2008) have suggested that oscillating or overturning air parcels could be brought repeatedly to water saturation allowing a quasi-steady-state to occur. Rauber and Tokay (1991) offered an alternative explanation for the persistence of mixed-phase conditions, noting that the supercooled droplets are often confined to a thin layer near cloud top, and this is also where crystals tend to be smallest (since the larger particles fall out). The vapour flux to each individual crystal is proportion to the size of the ice particles (Pruppacher and Klett 1997; Westbrook et al. 2008), and hence the smaller crystals induce a smaller depletion of liquid water and a longer-lived mixed-phase cloud. They also emphasised the possible significance of additional condensation via radiative cooling.

In section 5 we directly estimate the vapour flux within our mixed-phase layer cloud using in-situ data, and compare this value to the liquid water path, allowing us to establish a glaciation time scale for the cloud.

\section{Case study: 18 Feb 2009}

An overview of the synoptic conditions for this day has been given by Crosier et al. (2011): here we summarise the features pertinent to the present analysis. On 18 Feb 2009 a widespread band of mid-level cloud was present over much of the United Kingdom. This band became quasi-stationary over central and southern England, allowing detailed radar and in-situ measurements to be made over several hours.

Figure 1 shows a schematic diagram of this mid-level altocumulus cloud layer, inferred from the observational data. At cloud top $\left(\approx 3600 \mathrm{~m},-13.5^{\circ} \mathrm{C}\right)$ a thin layer of supercooled-liquid water droplets is present. Within this layer, ice crystals are being nucleated and grow quickly by vapour deposition in the supersaturated conditions. These crystals then fall out of the layer, forming virga below liquid cloud base $(\approx 3350 \mathrm{~m})$. As these crystals fall into drier air below, they gradually evaporate. Some of the crystals survived long enough to seed low-level stratus clouds in the boundary layer which were also present, leading to light drizzle at the surface.

The cloud cools from the top due to emission of longwave radiation to space; because of this the thermodynamic profile of the top $500 \mathrm{~m}$ or so is destabilised, and mixing occurs over this depth, encompassing both the supercooled layer and the uppermost part of the ice virga. Below this, the virga is stable and little mixing occurs. This microphysical and thermodynamic profile is similar to previous observations of thin mid-level clouds (Westbrook et al. 2010a). 


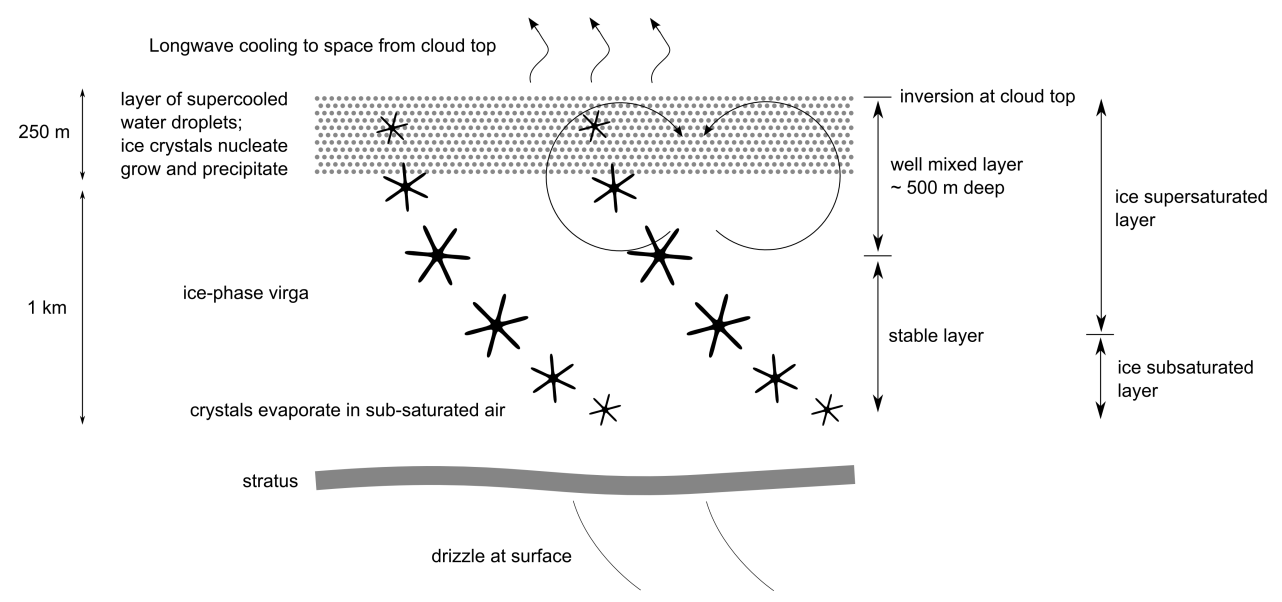

Figure 1. Schematic of mixed-phase cloud layer structure, 18 February 2009. Note the vertical scale of the low-level stratus and drizzle has been to compressed in order to emphasise the structure of the mid-level mixed-phase cloud.

We now discuss the evidence for the schematic picture outlined above. Figure 2 shows the ascent from a radiosonde launched at Larkhill, $25 \mathrm{~km}$ west of Chilbolton at 1101 UTC. This sounding contains a thin water-saturated layer at $650 \mathrm{hPa}\left(3.6 \mathrm{~km}\right.$ height), capped by a $4^{\circ} \mathrm{C}$ temperature inversion. The air above this inversion is extremely dry (7\% relative humidity). The thin water-saturated layer has a cloud top temperature of $-13.5^{\circ} \mathrm{C}$, and there is a well-mixed layer of air $(\approx$ constant equivalent potential temperature) extending down from cloud top to $700 \mathrm{hPa}$ $(3.1 \mathrm{~km})$. Beneath this, the profile becomes more stable, decoupling the liquid cloud from the drier air below. At lower levels $(<1500 \mathrm{~m})$, the profile is again close to water-saturation and the lidar ceilometer at Chilbolton (not shown) indicated the presence of thick boundary-layer stratus clouds throughout the day. Note that the winds were extremely slack, with speeds less than $5 \mathrm{~ms}^{-1}$ at all heights between the surface and cloud top; the vertical wind shear was minimal, $<0.005 \mathrm{~s}^{-1}$.

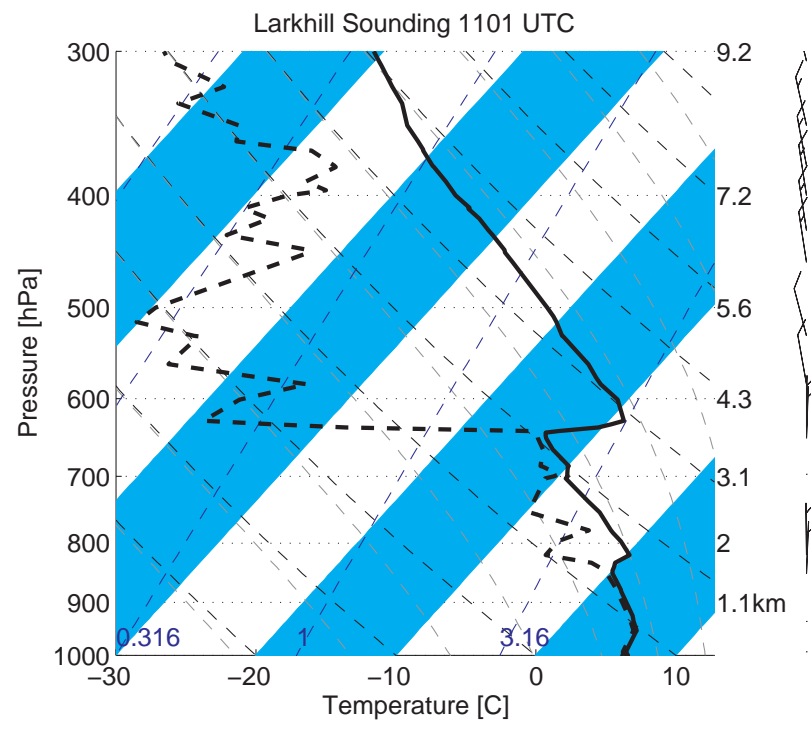

Figure 2. Sounding from Larkhill at 1101 UTC, 18 February 2009 plotted as a skew $\mathrm{T}-\log \mathrm{P}$ diagram. Note that the numbers on the right hand side indicate geopotential height [in $\mathrm{km}]$ at various pressure levels.

Figure 3 shows the time series from the verticallypointing cloud radar at Chilbolton for the period during which in-situ measurements were made (radar observations were collected over a much longer period, as discussed in section 2.2). This instrument operates at a wavelength of $8.6 \mathrm{~mm}$, and provides vertical profiles with $60 \mathrm{~m}$ range resolution every 30s (Illingworth et al. 2007). Because the radar reflectivity $Z$ is proportional to the mass ${ }^{2}$ of the scatterer, it is insensitive to small cloud droplets, and in mixed-phase clouds the radar signal is typically dominated by any ice particles that are present. The values of $Z$ observed in the supercooled layer and virga $(\approx-10$ to $0 \mathrm{dBZ}$ ) are comparable in magnitude to the observations by Westbrook et al. (2010a) and indicate ice water contents in the range $\sim 0.01-0.04 \mathrm{gm}^{-3}$ (Hogan et al. 2006). Note that the reflectivity decreases as the crystals fall below $\approx 2800 \mathrm{~m}$, either evaporating completely, or intermittently seeding lower level clouds producing light drizzle at the surface $\left(-5 \mathrm{dBZ}\right.$ corresponds to $\approx 0.03 \mathrm{mmhr}^{-1}$ Westbrook et al. 2010b).

Figure $3 \mathrm{~b}$ shows the Doppler velocity from the cloud radar. Negative values indicate crystals falling towards the radar: the mean Doppler velocity in the virga is $0.75 \mathrm{~ms}^{-1}$ - note however that like the reflectivity this is weighted towards the heaviest ice particles. Superimposed on the terminal velocity of the ice crystals are the turbulent vertical air motions present within the top $500 \mathrm{~m}$ of cloud. This turbulence is more clearly visualised by computing $\sigma_{\langle v\rangle}$ the standard deviation of the 1-s mean Doppler velocity over 30 s intervals, as shown in figure 3c. Since the terminal velocity of snowflakes varies weakly over this short time period, this quantity simply reflects the variability in the vertical wind, and is proportional to the cube root of the eddy dissipation rate $\epsilon$ (Bouniol et al. 2003). Values of $\sigma_{\langle v\rangle}$ up to $0.4 \mathrm{~ms}^{-1}$ are observed in the top $500 \mathrm{~m}$ of cloud, decreasing sharply to a mere $\sim 0.04 \mathrm{~ms}^{-1}$ in the bulk of the virga (note the logarithmic colour scale) indicating stable, quiescent conditions, where $\epsilon$ is three orders of magnitude lower than in the well-mixed layer.

\subsection{In-situ sampling and coincident radar observations}

A series of profiles and straight and level runs were performed to the west and overhead Chilbolton, both within the supercooled cloud layer and its virga, between 1148 and 1617 UTC (note the timescale in figure 3 has been chosen to match this time period). Figure 4 shows a profile 
(a) Radar reflectivity - vertically pointing cloud radar [dBZ]

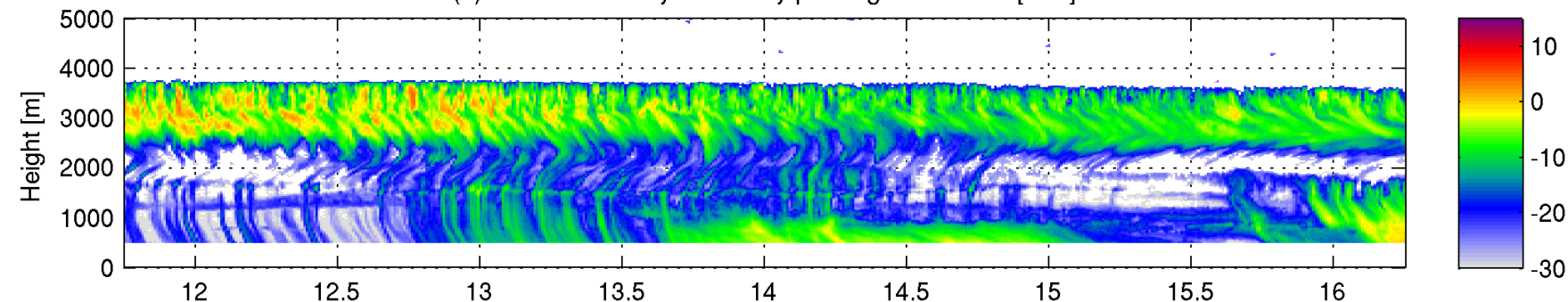

(b) Doppler velocity $[\mathrm{m} / \mathrm{s}]$

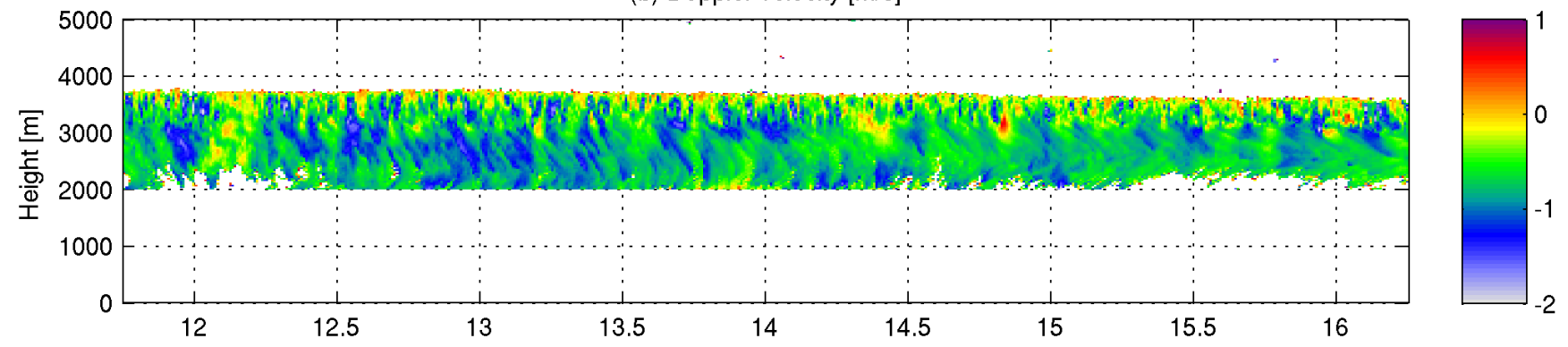

(c) Turbulent air motion $\sigma_{<v>}[\mathrm{m} / \mathrm{s}]$

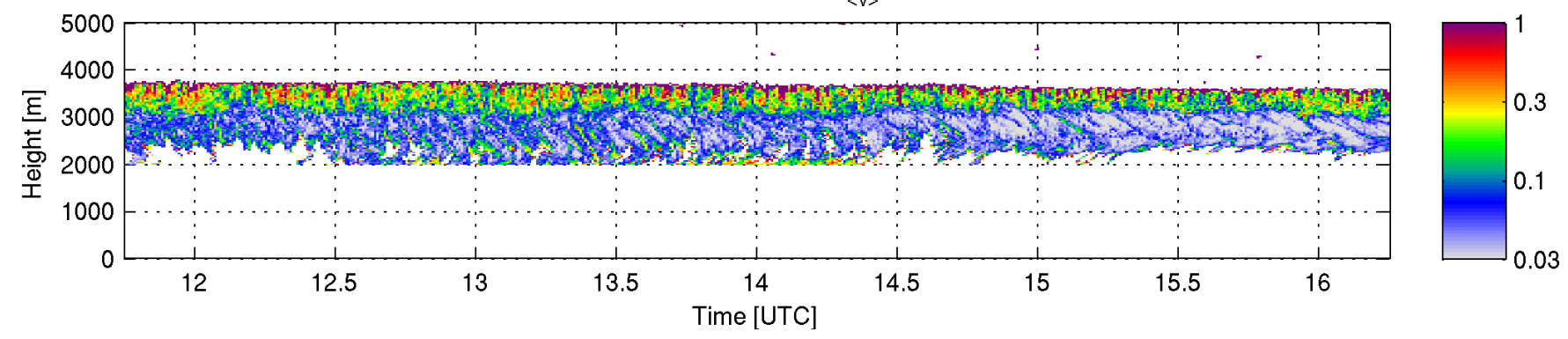

Figure 3. Zoomed-in time series from vertically pointing $35 \mathrm{GHz}$ radar at Chilbolton during in-situ sampling period on 18 February 2009 . Panels show (a) radar reflectivity, (b) Doppler velocity (note convention of negative velocities towards the radar) and (c) standard deviation of 1-s Doppler velocity over 30s intervals (note the $\log _{10}$ colour scale). In panels (b) and (c) all data points below $2000 \mathrm{~m}$ have been removed.

through the supercooled layer at 1454 UTC from a forwardscattering cloud droplet probe (CDP - Droplet Measurement Technologies Inc, USA). The concentration of droplets was approximately constant with height at $70 \mathrm{~cm}^{-3}$, while the liquid water content increases approximately linearly between cloud base and cloud top. The gradient of liquid content with height is consistent with that expected from an adiabatic ascent at this temperature and pressure, as illustrated by the dashed line (Brenguier et al. 1991). The peak liquid water content was $0.2 \mathrm{gm}^{-3}$, and the liquid water path was $21 \mathrm{gm}^{-2}$. The similarity between the observed and adiabatic profiles, and the constant profile of droplet concentration supports the notion that the supercooled layer is well mixed. The rather modest liquid water path is typical of mid-level mixed-phase clouds (Hogan et al. 2003).

Figure 5 shows a section of a range-height indicator $(\mathrm{RHI})$ scan from the steerable 'CAMRa' radar $(25 \mathrm{~m}$ antenna, $10 \mathrm{~cm}$ wavelength - see Goddard et al. 1994 for full details), sampled at 1221 UTC. The FAAM aircraft was sampling the supercooled layer near cloud top at this time, and was flying in the same plane as the RHI scan. The aircraft flight track is indicated by the solid line on figure $5 \mathrm{a}$, which is overlaid on the radar reflectivity field. As for the cloud radar observations, reflectivities in the range -10 to OdBZ were typically observed. This radar also has dualpolarisation capability, and figure 5 b shows the differential reflectivity $Z_{D R}$, which is the ratio of co-polar radar reflectivity for horizontal and vertically polarised waves. Particles with no preferred alignment such as irregular polycrystals or aggregates typically have $Z_{D R}=0-0.5 \mathrm{~dB}$ (Hogan et al. 2012); likewise spherical drizzle drops also have $Z_{D R}=$ $0 \mathrm{~dB}$. However in this case we observe $Z_{D R}$ in the range $0.5-3 \mathrm{~dB}$, confirming that the virga are ice particles and that they are likely pristine, horizontally-oriented ice crystals (Hall et al. 1984; Hogan et al. 2002; Westbrook et al. 2010a). Westbrook et al. (2010a) presented evidence that such crystals were common in the virga beneath supercooled layers. Figure 5e shows images of ice particles, sampled using a 2DS optical array probe (Lawson et al. $2006)$ at a corresponding point in the aircraft run $(25-50 \mathrm{~km}$ west of Chilbolton), confirming that the crystals in this cloud were indeed predominantly pristine, vapour-grown crystals of the planar type. Figures 5c,d show fluxes of ice number and mass computed from the in-situ size spectra, and these will be discussed in sections 3 and 4 respectively.

The horizontal homogeneity of the cloud layer is illustrated in figure 6 which shows a photograph taken on a run at $4000 \mathrm{~m}$ (above the supercooled cloud layer). Note the flat top, produced by the sharp inversion. Also note the cellular structure indicative of the shallow convective overturning occurring in the top $500 \mathrm{~m}$ of cloud. The structure is reminiscent of photographs of stratocumulus sheets from above (eg. Nicholls and Leighton 1986). 

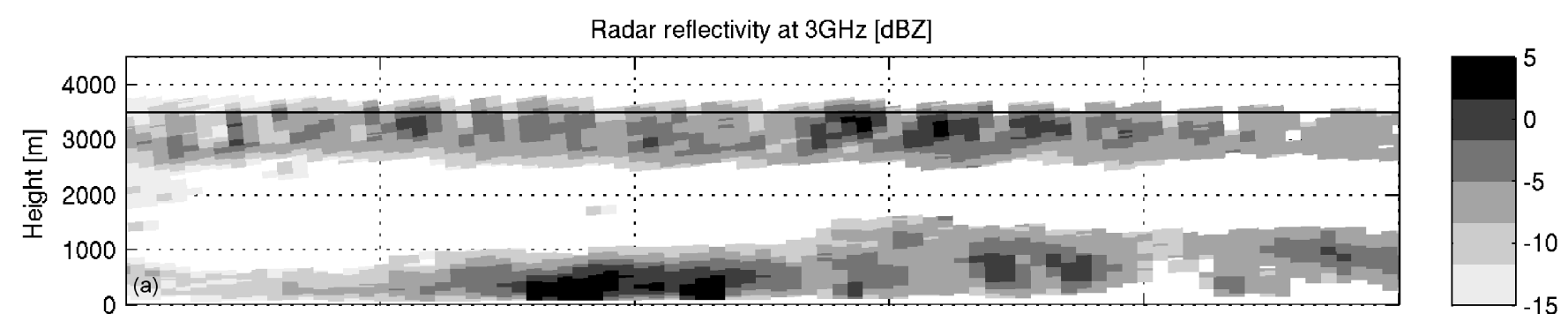

Differential reflectivity $[\mathrm{dB}]$
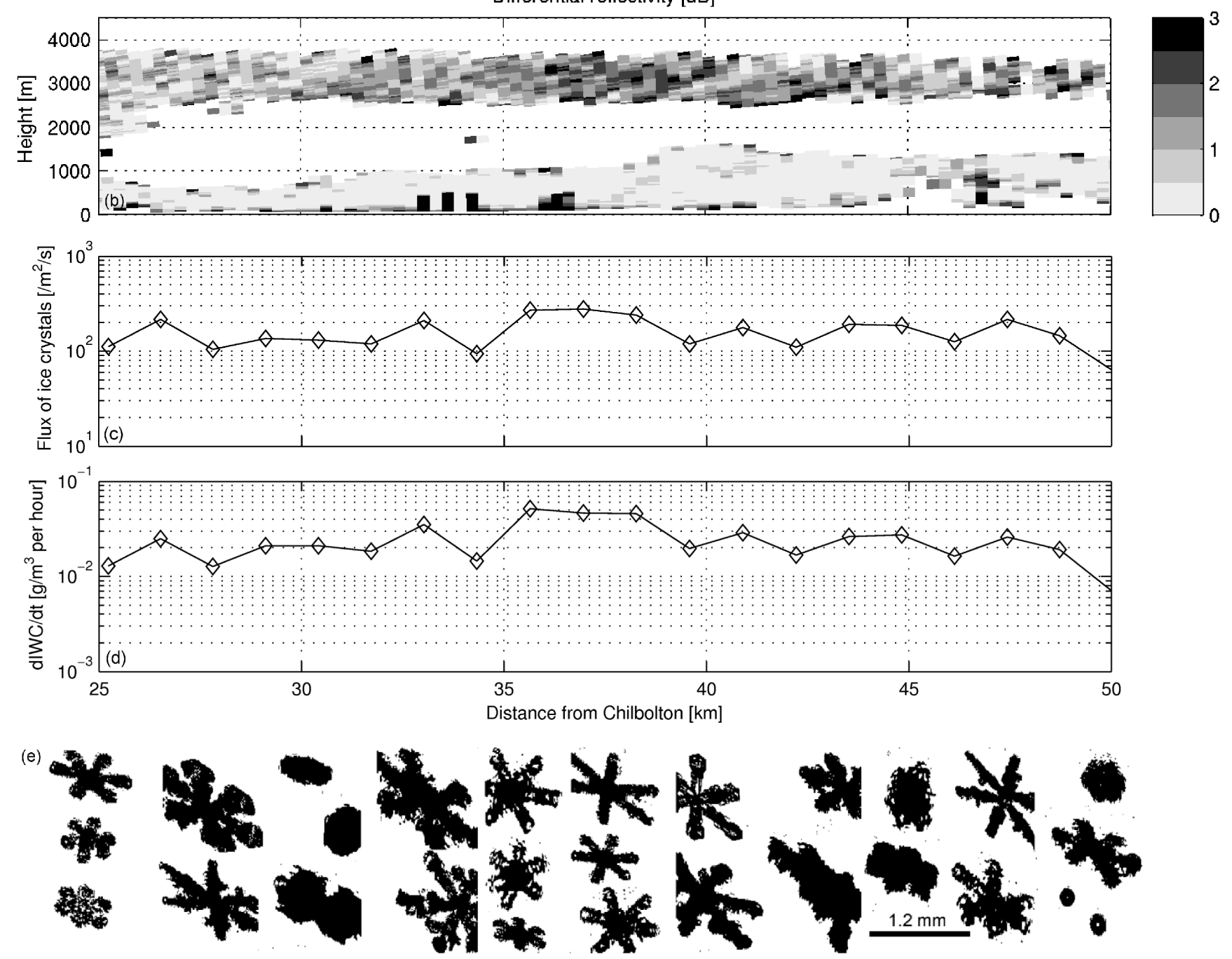

Figure 5. (a) Radar reflectivity and (b) Differential reflectivity from RHI scan at 1221 UTC, 18 Feb 2009. Note that the minimum detectable reflectivity for the CAMRa radar at $40 \mathrm{~km}$ range is $\approx-7 \mathrm{dBZ}$; returns below $1500 \mathrm{~m}$ are drizzle from low-level clouds. Data has been averaged to $300 \mathrm{~m}$ range resolution. Panels (c,d,e) are in-situ data collected simulateously during a straight and level run at 3480m height. Panel (c) shows the number flux of ice crystals falling through the mixed-phase layer; panel (d) shows an estimate of the rate of vapour growth of the ice crystals (see text for details). Panel (e) shows a selection of the crystals sampled.

In addition to the widespread layer cloud there was also some weak $\left(1 \mathrm{~ms}^{-1}\right.$ peak updraught, $1 \mathrm{mmhr}^{-1}$ peak rainrate) embedded convection triggering at mid-levels along a narrow $(<4 \mathrm{~km}$ wide $)$ convergence line $\approx 20 \mathrm{~km}$ west of Chilbolton. This feature was analysed in detail by Crosier et al. (2011) who determined that rime-splinter ice multiplication was occurring in these cells. Here we simply note that we have excluded parts of the aircraft runs which were affected by this feature from the analysis of the layer cloud that follows in sections 3,5 .

\subsection{Persistence over 1 day}

The analysis above has focussed on a $4.5 \mathrm{hr}$ period during which the aircraft and scanning radar measurements were collected. However, the cloud radar at Chilbolton operates continuously, allowing us to study the persistence of the cloud layer. Figure 7 a shows the radar reflectivity time series between 0830 UTC on 18 Feb and 0830 UTC on $19 \mathrm{Feb}$. The quasi-steady nature of the cloud layer is clear from this figure - cloud top is $\approx$ constant between 0830 and midnight, and ice production during this period appears to be quite steady also. Over the following 8.5 hours the field is more broken and cloud top lowers slightly. Figure $7 \mathrm{~b}$ shows 
(a)

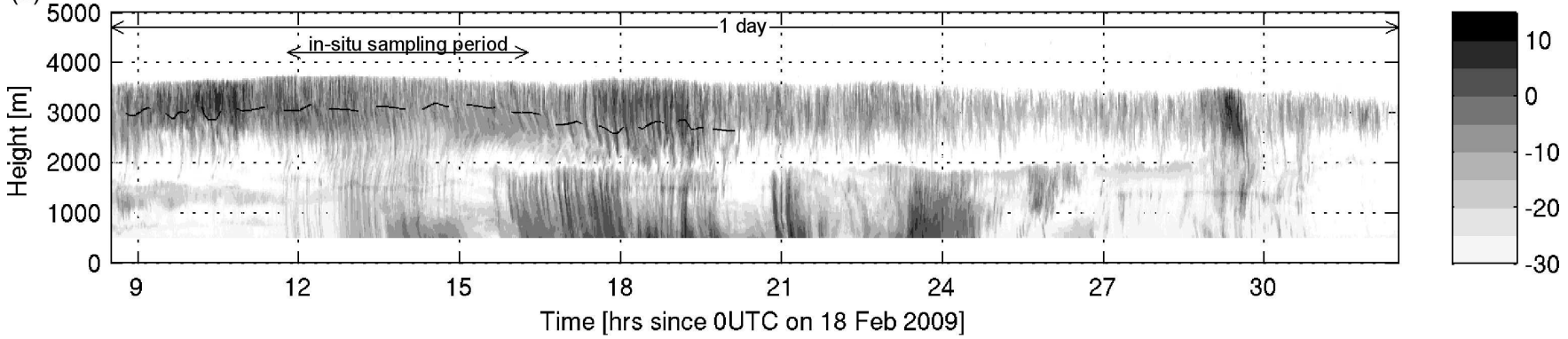

(b)
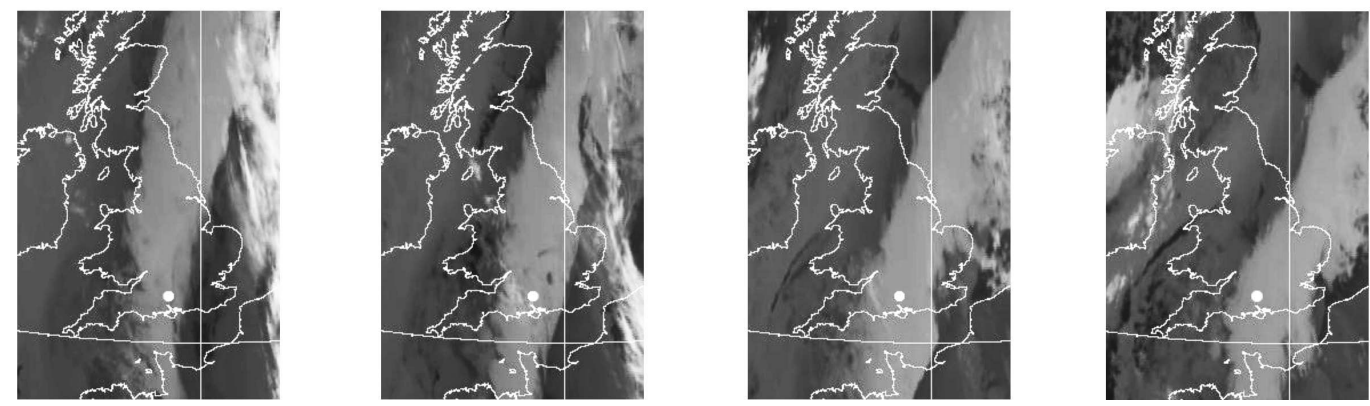

Figure 7. (a) Time series of reflectivity from vertically pointing $35 \mathrm{GHz}$ radar at Chilbolton over 24 hour period (as indicated by long arrow). Inset arrow indicates period during which in-situ sampling occurred, and corresponds to the time range shown in figure 3 . Dashed line indicates the lower boundary of the well-mixed layer at the top of the cloud, diagnosed from Doppler $\sigma_{\langle v\rangle}$ measurements (see text for details). After 20 UTC the full depth of the virga is turbulent. (b) Geostationary infrared satellite images from Meteosat Second Generation at 09, 15, 21 and 27hrs. White dot indicates location of Chilbolton.

a sequence of infrared geostationary satellite images during the course of the 1 day period. The mid-level cloud band is well defined; the position of Chilbolton on these images is shown by the white dot.

Also shown in figure $7 \mathrm{a}$ is the lower boundary of the well-mixed layer as derived from the $\sigma_{\langle v\rangle}$ measurements. This was estimated for each vertical profile by moving down from cloud top to the point where $\sigma_{\langle v\rangle}<0.1 \mathrm{~ms}^{-1}$. As before, we find this mixed-layer depth to be $\approx 500 \mathrm{~m}$ throughout the day, until 2000 UTC, after which the whole depth of the virga is diagnosed to be turbulent. This deepening of the mixed layer may perhaps be the result of stronger long-wave cooling during the night.

\section{Ice nucleus budget}

In this section we attempt to quantify the budget of available ice nuclei. To do this, we have used the in-situ size spectra to estimate the flux of ice crystals precipitating from the supercooled layer, which equals the sink of ice nuclei from the cloud layer. This flux is:

$$
\text { Flux }=\int_{0}^{\infty} n(D) v(D) \mathrm{d} D
$$

where $D$ is the maximum dimension of the ice particles, $n(D)$ is their size distribution sampled by the 2DS probe, and $v(D)$ is their terminal velocity. The size spectra were integrated over 10s $(\sim 1 \mathrm{~km})$ before computing the moment (1). We did not observe significant numbers of large snowflakes in the cloud, presumably because the layer is rather shallow. Consequently, any artefacts due to shattering of large particles on the tips of the probe (Korolev and Isaac 2005; Field et al. 2006) are expected to be minimal. To further assure the quality of our flux estimates, interrarival time filtering was applied to the data (see Crosier et al. 2011), Korolev and Isaac (2005)'s algorithm to filter out shattered images has been applied to the size spectra, and we have also elected to only consider particles $>100 \mu \mathrm{m}$ in size to further minimise the sensitivity of our calculations to any possible shattering artefacts. Relaxing this size threshold to $50 \mu \mathrm{m}$ was found to have a negligible effect on the results. Data collected using a CIP optical array probe mounted on the same aircraft gave identical results to with $15 \%$.

The fall speeds of the ice crystals as a function of their size was estimated using the relationship for stellar crystals given in Heymsfield and Kajikawa (1987). Figure 5c shows a time series of the calculated flux, assuming the $v(D)$ relationship for stellar crystals. This time series is over a $25 \mathrm{~km}$ segment of a straight and level run just below cloud top (3480m), coinciding with the RHI scan shown in figure $5 \mathrm{a}, \mathrm{b}$. The flux is quite consistent over this leg, and values of $\sim 150 \mathrm{~m}^{-2} \mathrm{~s}^{-1}$ were observed.

We now proceed to compute the average flux computed for 6 in-situ runs, shown in figure 8. Since a mixture of different planar crystal shapes from solid plates to thin branched crystals were observed (figure 5e), we have computed these fluxes assuming a variety of $v(D)$ curves (see table 1 for details), and then quote the range of values predicted by those different assumptions (typically $\pm 35 \%$ of the mid point). The velocities were adjusted for the air density at the cloud top (Heymsfield and Kajikawa 1987).

As mentioned above, we have isolated and removed the convective feature studied by Crosier et al. (2011), blanking out data $10 \mathrm{~km}$ either side of the convective element. The consistency of the computed fluxes along the radial (eg $5 c$ ) is evidence that this feature did not affect our analysis of the layer cloud. We also note that the mean wind is northerly in this case study, hence any crystals produced by the convective feature will be advected out of the plane of the radar scans and the aircraft sampling path.

The mean fluxes in figure 8 appear to be approximately constant with height at $\approx 100 \mathrm{~m}^{-2} \mathrm{~s}^{-1}$, and are consistent between the earliest and latest runs which are 3 hours 

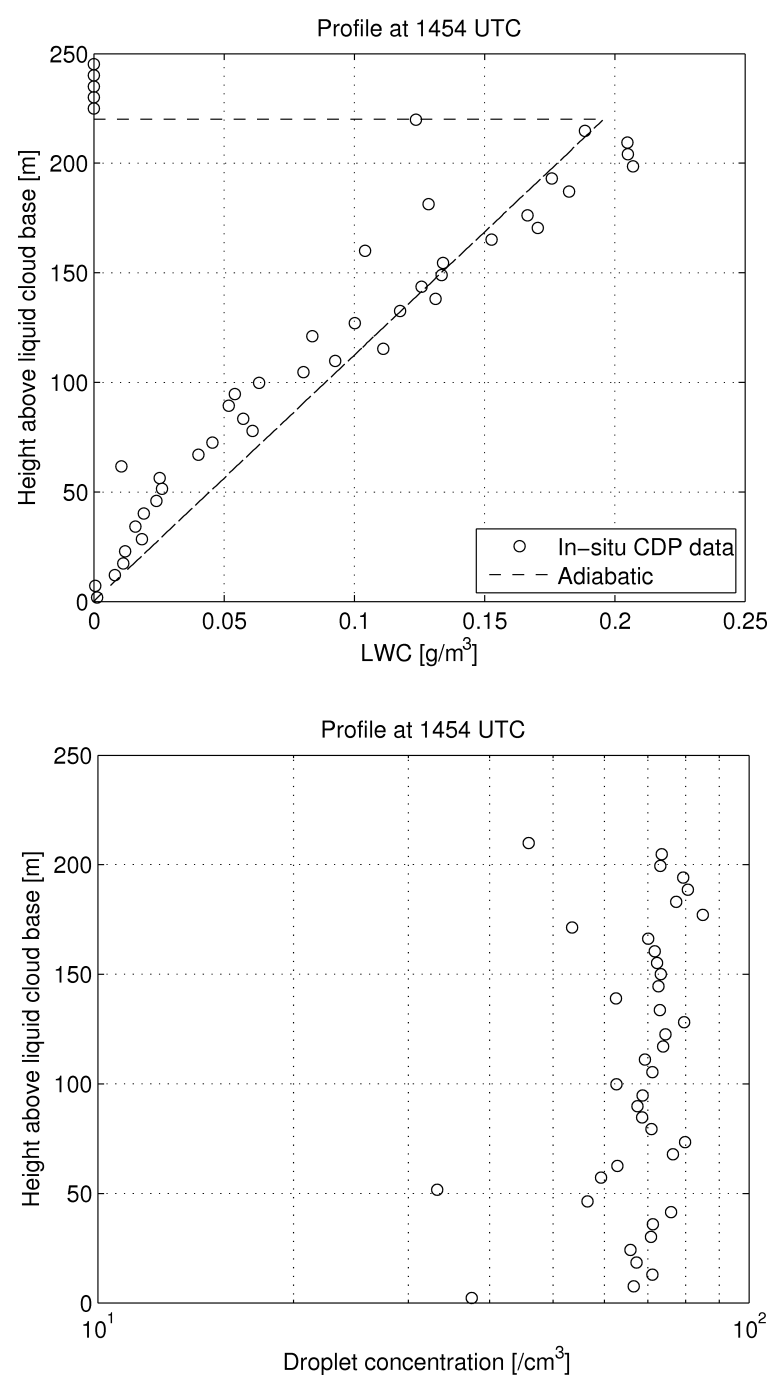

Figure 4. Profile of liquid water content (top) and droplet number concentration (bottom) in supercooled cloud layer measured in-situ with a forward-scattering Cloud Droplet Probe (CDP). Note the height axis has been normalised relative to the base of the liquid cloud. Dashed line shows the theoretical adiabatic profile predicted for a layer at this temperature and pressure.

Table 1. Fall speed relationships used to compute ice fluxes - from Heymsfield and Kajikawa (1987) $v=a D^{b}$. Here $v$ is in $\mathrm{cms}^{-1}$ and $D$ is in $\mathrm{cm}$.

\begin{tabular}{ccc}
\hline Crystal habit & $\mathrm{a}$ & $\mathrm{b}$ \\
\hline Hexagonal plate & 297 & 0.86 \\
Sector plate & 190 & 0.81 \\
Broad branch & 103 & 0.62 \\
Stellar & 58 & 0.55 \\
Dendrite & 55 & 0.48 \\
\hline
\end{tabular}

apart. This is evidence that: (a) the formation of ice in the supercooled cloud is approximately in a steady state (at least over the time scale of a few hours), and (b) aggregation is relatively unimportant in this cloud, since the number flux does not decrease with height. The latter point appears to be consistent with the crystal images shown in figure 5e which are predominantly vapour-grown single crystals.

To give a more comprehensive picture of the ice microphysics, in addition to the fluxes we have also computed the concentration of ice particles $>100 \mu \mathrm{m}$ in size, as shown in figure 9. Average concentrations over the

\section{8/Peb/09 12:01:51}

Figure 6. Photograph of supercooled layer cloud from above, sampled from rear-facing video camera on the FAAM aircraft. Note the well defined flat top, and hexagonal cellular cloud structure indicating shallow convection similar that observed in stratocumulus.

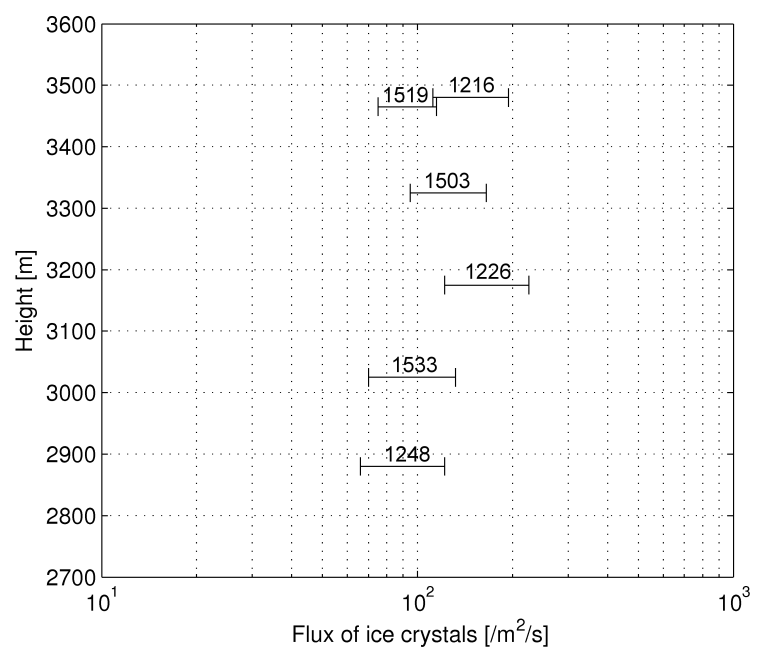

Figure 8. Flux of ice crystals calculated from in-situ size spectra during as a function of height. Fluxes are average for the complete run. Error bar shows spread of values obtained for different $v(D)$ relationships assumed - see text for details. Start time of each aircraft run [UTC] is noted by each flux estimate.

runs were estimated to lie in the range $600-1300 \mathrm{~m}^{-3}$ : no clear trend between concentration and height was observed. Details of the size spectra have been presented previously by Crosier et al. (2011), and did not show any systematic variation over this relatively shallow height interval.

Figure 10 shows the flux-weighted mean size of the ice crystals, defined as:

$$
\langle D\rangle_{f l u x}=\frac{\int_{0}^{\infty} n(D) v(D) D \mathrm{~d} D}{\int_{0}^{\infty} n(D) v(D) \mathrm{d} D} .
$$

This figure shows that the particles which contribute most to the particle flux are typically $\approx 300 \mu \mathrm{m}$ in size: this was found to be approximately constant over the height range sampled. 


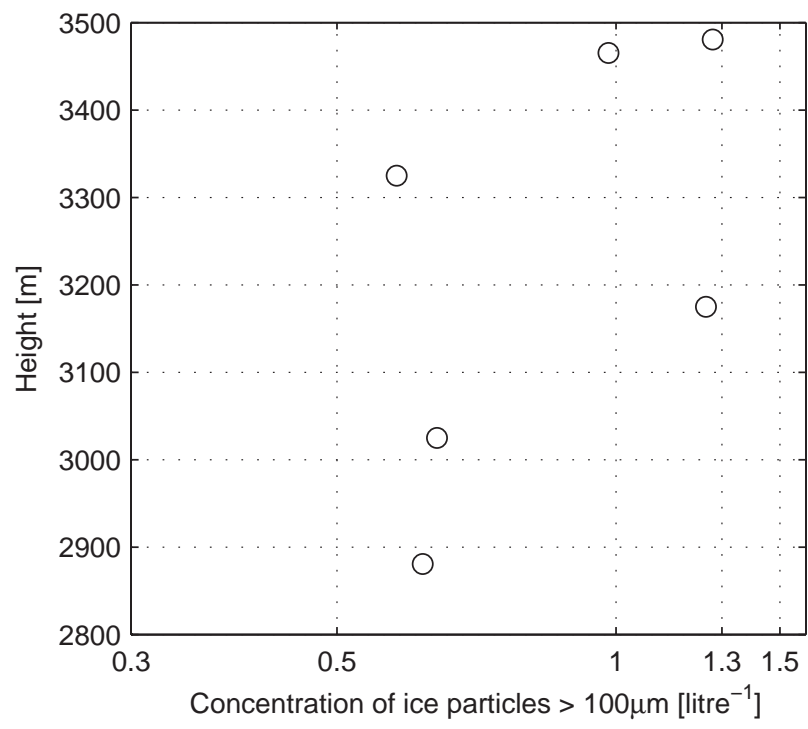

Figure 9. Run-averaged concentrations of ice particles larger than $100 \mu \mathrm{m}$ as a function of height.

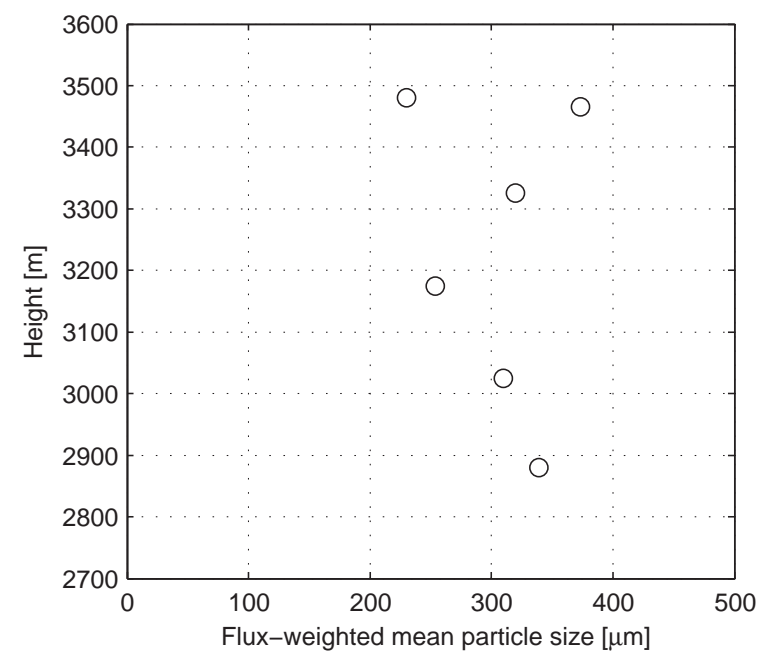

Figure 10. Flux-weighted mean size of ice crystals calculated from insitu size spectra during as a function of height. Fluxes are average for the complete run (runs are same as in figure 8

\subsection{Comparison with parameterisation of ice nuclei concentrations}

We now attempt to reconcile our observed fluxes with the likely concentration of available ice nuclei. No in-situ ice nuclei measurements were available. However, based on the temperature-dependent fit given in DeMott et al. (2010) from a compilation of continuous flow diffusion chamber observations in many clouds, at $-13.5^{\circ} \mathrm{C}$ (the temperature at cloud top) we should expect $\sim 600$ active ice nuclei per cubic metre of air. Since such instruments have a residence time of a few seconds at most, we take this concentration to represent the number of rapidly activated (quasi-singular) ice nuclei which could potentially be activated in the cloud. Multiplying this concentration by the depth of the well mixed layer shown in figure $3(\approx 500 \mathrm{~m})$ we obtain a total of $3 \times 10^{5} \mathrm{~m}^{-2}$ nuclei which are potentially available for ice formation. If these are removed by ice crystal formation at the rate estimated above, these nuclei will be completely depleted in 3000s - less than 1 hour. Clearly this is not the case - we have observed a steady flux of crystals falling from the supercooled cloud layer for 3.3 hours in-situ, and for 24 hours with the radar.

In addition to a temperature-dependent fit, DeMott et al. (2010) has also suggested a refined correlation using the number of aerosol particles $>0.5 \mu \mathrm{m}$ as a secondary parameter. In-situ aerosol measurements were not possible within the cloud layer itself; data from a PCASP probe sampling below and above the cloud layer (Crosier et al. 2011) reveal concentrations of these large aerosol particles of $<0.25 \mathrm{~cm}^{-3}$. Applying this value to DeMott et al. (2010)'s equation (1) leads to a predicted concentration approximately half of the one calculated above, and an even shorter depletion timescale.

\subsection{Attempts to reconcile the observed fluxes with expected ice nucleus concentrations}

In what follows we discuss a number of possible explanations for the discrepency between the flux of ice crystals being nucleated in the supercooled layer, and the expected concentration of nuclei available, based on previous measurements. Our purpose here is to investigate possible mechanisms whereby the singular approximation can be reconciled with our flux observations.

\subsubsection{An unusually high concentration of ice nuclei are present.}

The calculations in section 3.1 assumed a typical concentration of $600 \mathrm{~m}^{-3}$ active nuclei available at the cloud top temperature. However, in the compilation of ice nucleus measurements presented in DeMott et al. (2010) there are a number of data points significantly higher than the value parameterised based on temperature alone. The highest of these in the temperature range considered is $\approx 4000 \mathrm{~m}^{-3}$ (6.7 times higher than assumed in our baseline calculation in section 3.1). Assuming this higher concentration of available nuclei complete depletion would occur within $5.5 \mathrm{hrs}$, yet there was no change in the in-situ fluxes over $3.3 \mathrm{hrs}$; and we observe continuing ice production with the radar for 24 hours. In fact $\approx 3 \times 10^{4} \mathrm{~m}^{-3}$ active nuclei would be required to explain the sustained production of ice at the observed level for 24 hours. This is inconsistent with DeMott et al. (2010) who observed such concentrations extremely rarely, and exclusively in clouds colder than $\approx$ $-24^{\circ} \mathrm{C}$.

\subsubsection{Cloud top is cooling slightly leading to more active} nuclei.

We expect the cloud to be emitting infrared radiation to space and hence cooling from the top - this is very likely to be the cause of the mixing observed in the top $500 \mathrm{~m}$ as the temperature profile is destabilised by this cooling. Soundings from Larkhill ( $25 \mathrm{~km}$ to the west of Chilbolton), Herstmonceux (100km south east of Chilbolton) and Nottingham (200km north of Chilbolton) through 18 and $19 \mathrm{Feb} 2009$ suggest that cloud top cooled by at most $1.5 \mathrm{~K}$ in the time it was present over Chilbolton. This cooling increases the number of active nuclei by a mere $20 \%$ according to DeMott et al. (2010), and cannot compensate for the observed loss of nuclei. 


\subsubsection{Fresh nuclei are being entrained from above cloud} top.

Given the humidity profile shown in figure 2, it is clear that the air immediately above cloud top is extremely dry (7\% relative humidity with respect to liquid water). Entrainment rates in stratocumulus clouds are typically of order $\sim 0.01 \mathrm{~ms}^{-1}$ (Stevens 2002), and there seems no reason to suspect substantially stronger entrainment in this mid-level cloud. Indeed, cloud top remains at an almost constant altitude over the entire 24 hour period shown in figure $7 \mathrm{a}$, suggesting any entrainment is extremely weak. To mix dry air in at a rate which compensates for the loss of crystals through sedimentation $\left(\approx 0.1 \mathrm{~ms}^{-1}\right)$ would lead to rapid evaporation of the liquid droplets and dissipation of the cloud layer, which we do not observe.

\subsubsection{Fresh nuclei are sedimenting from above cloud top.}

The sedimentation rate of a $1 \mu \mathrm{m}$ aerosol particle is $\sim$ $3 \times 10^{-4} \mathrm{~ms}^{-1}$ at this altitude (Pruppacher and Klett 1997). Even if one assumes a (upper limit) concentration of $4000 \mathrm{~m}^{-3}$ ice nuclei immediately above the cloud layer, the sedimentation flux is a mere $1 \mathrm{~m}^{-2} \mathrm{~s}^{-1}$, two orders of magnitude lower than the observed flux of crystals.

\subsubsection{Fresh or recycled nuclei are being recycled from below base of virga.}

The eddy dissipation estimates in figures 3,7 (discussed in section 2) indicate that the depth of the well-mixed layer extends approximately $500 \mathrm{~m}$ below cloud top for the first $12 \mathrm{hrs}$ during which the layer was observed, while the air is stable and stratified below. Note that the depth of this layer is less than the depth of the virga, as observed by the radar, so nuclei from evaporated ice crystals cannot be recycled. This conclusion is also supported by measurements of relative humidity $R H_{i c e}$ with respect to ice made in-situ using a chilled-mirror hygrometer. The average values of $R H_{\text {ice }}$ computed for each aircraft run at various levels are presented in figure 11, and show that the air is at or above ice saturation from $\approx 2700 \mathrm{~m}$ to cloud top (for comparison the well-mixed layer extends down to $\approx 3100 \mathrm{~m}$ in figure 3 ). A similar structure of a well-mixed layer at cloud top, with a stable virga below was also observed by Westbrook et al. 2010a.

Overnight the turbulent layer did deepen, ultimately encompassing the whole depth of the virga (from 20 UTC onwards, see figure 7). During this later portion of the cloud evolution some nuclei could potentially be recycled.

\subsubsection{Ice multiplication is occurring.}

The only established ice multiplication mechanism is rimesplintering which occurs exclusively between -3 and $-8^{\circ} \mathrm{C}$ (Pruppacher and Klett 1997). Since our supercooled cloud did not span this temperature range, and since riming of the crystals themselves was minimal (see figure 5) we do not believe that multiplication occurred in this cloud layer.

\section{Discussion: evidence for time-dependent freezing}

None of the hypotheses above appears to offer a satisfactory explanation for the persistent flux of ice observed to be

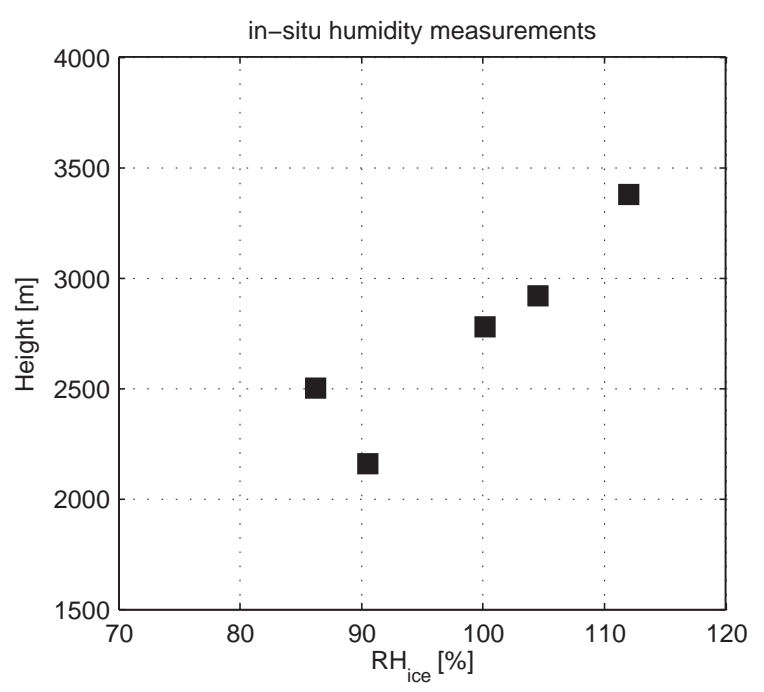

Figure 11. Relative humidity measured in-situ. Values are averages for each aircraft run at the heights shown.

precipitating from this cloud. The observation of a quasisteady flux of ice from a cloud where there is a substantial sink of ice particles (precipitation) but no major source of fresh ice nuclei strongly suggests that nucleation is not a quasi-singular process, but may be occurring on time scales much longer than previously suspected.

Fridlind et al. (2012) found a similar discrepancy in cloud-resolving model simulations of a long-lived mixedphase boundary layer cloud in the arctic. Similar to our analysis, they predicted that the available ice nuclei would be rapidly consumed and depleted by precipitation, and that maintaining the observed concentration of ice crystals would require either an unfeasibly rapid entrainment rate at cloud top, or an unfeasibly large number of ice nuclei in the air immediately above the cloud.

To explain our observations, and those of Fridlind et al. (2012), we propose that in these weakly-forced, long-lived layer clouds, droplets freeze slowly and steadily over time, producing the light steady precipitation of snow observed. We suggest that there exists a broad spectrum of ice nuclei activity in a typical supercooled cloud: a small number of nuclei which are extremely efficient (quasi-singular, as sampled by IN counters) and a much larger number which are very inefficient and are activated slowly over many hours (quasi-stochastic). In the updraught of a cumulus cloud where a parcel is rapidly cooled the former will dominate the formation of ice in the cloud. However in long-lived, weakly-forced layer clouds in which the droplets remain at a fixed temperature for long periods of time, the stochastic nuclei would become dominant, slowly being activated over many hours as we observe.

To support the mechanism outlined above, we briefly review past laboratory studies which support the idea that there is a significant time-dependence to ice nucleation.

\subsection{Laboratory evidence for time-dependent freezing}

Vonnegut (1949) was amongst the earliest to suggest that ice nucleation was a time-dependent process. In cold box experiments he created a supercooled cloud at $-17^{\circ} \mathrm{C}$, and found that when ice was nucleated heterogeneously through the introduction of silver iodide smoke into the box, a significant flux of ice particles were observed over 
the course of an hour, consistent with a time-dependent nucleation process. The mode of nucleation is not clear in these experiments, and losses to the walls of the box over the hour-long experiment were not quantified - hence Vonnegut describes his conclusion as 'tentative'. In a separate study, Vonnegut (1948) placed 64 drops of water (3mg mass) onto a cooling stage (chrome sheet covered with a thin polystyrene film). The source of nuclei were impurities in the atmosphere (or perhaps impurities on the stage itself). Experiments were performed isothermally at $-14,-16$ and $-18^{\circ} \mathrm{C}$, and the number of drops was measured as a function of time. A strong time-dependence was observed in the freezing rate $P(T)$ : at $-16^{\circ} \mathrm{C}$ only half the drops had frozen after 20 minutes, whilst at $-18^{\circ} \mathrm{C}$ every drop had frozen within the first 10 minutes.

Vali and Stansbury (1966); Vali (1994, 2008) froze $0.01 \mathrm{~cm}^{3}$ water drops on a cold stage. Soil particles were immersed in the drops with the aim of mimicking natural ice nuclei. Experiments were performed where the stage was cooled steadily at $1^{\circ} \mathrm{Cmin}^{-1}$ (corresponding to an updraught of $\approx 2 \mathrm{~ms}^{-1}$ in the atmosphere); another set of experiments included periods of several minutes where the temperature was held constant. The rate of nucleation was found to be much faster during the periods of cooling than during the isothermal periods; Vali (2008) also observed that the temperature at which the drops froze was well-defined and varied relatively little from run-torun. However, a stream of freezing events did occur even when the temperature was held constant, demonstrating that the singular hypothesis is not accurate when cooling is sufficiently slow.

Progress in sampling a large number of freezing events with a single set of nuclei was made by Baldwin and Vonnegut (1982) and Vonnegut and Baldwin (1984) who placed $10 \mu \mathrm{L}$ of water in a glass tube, and added $0.01 \mathrm{~g}$ of Silver Iodide particles as ice nuclei. Automated apparatus was developed to cool the sample to a fixed temperature, wait for it to freeze, thaw it out, and repeat, allowing 850 separate experiments to be performed. The freezing times varied greatly from run to run, from $10 \mathrm{~s}$ to 300 s, consistent with a random freezing process. An exponential decrease in the average nucleation time was observed with increasing supercooling.

Following on from this work Barlow and Haymet (1995) and Heneghan et al. (2001) developed an improved version of the Vonnegut and Baldwin apparatus. Now a single, large Silver Iodide crystal was used as a nucleus (rather than a large number of potential nuclei mixed together) in a $500 \mu \mathrm{L}$ sample of water, and the source of the freezing could be visually confirmed as being the AgI crystal (rather than the glass tube). Again, experiments were isothermal, and the time to freezing was measured. At $-8^{\circ} \mathrm{C} 300$ runs were performed and a broad distribution of freezing times were observed. The freezing times from run to run were completely uncorrelated with one another, evidence that freezing was a random statistical process. Heneghan et al. $(2002 a, b)$ described a newer version of the apparatus with a smaller sample volume $(200 \mu \mathrm{L})$ and the ability to cool a sample steadily rather than performing only isothermal runs. A range of cooling rates $\left(0.6-7.5^{\circ} \mathrm{C} \mathrm{s}^{-1}\right)$ was used. Plotting the fraction of unfrozen samples as a function of supercooling produced curves which were independent of cooling rate. Assuming a random distribution of freezing times allows the average freezing time to be deduced, which is of order $100 \mathrm{~s}$ at $-5^{\circ} \mathrm{C}$ and a few minutes at $-7^{\circ} \mathrm{C}$ for $\mathrm{AgI}$.
Wilson and Haymet (2009) describe similar analysis where a $200 \mu \mathrm{m}$ sand particle was used as the ice nucleus rather than a Silver Iodide crystal - again a random, stochastic freezing behaviour was observed.

Murray et al. (2011) reported cold-stage experiments in which droplets containing Kaolinite particles were held at constant temperature. Like Heneghan et al. (2001) they observed a broad variation in the time taken for the droplets to freeze, from seconds up to $\sim 1 \mathrm{hr}$, and they found that statistics of the fraction of droplets unfrozen decreased exponentially with time, consistent with a stochastic process. Follow-up work by Broadley et al. (2012) using Illite as an ice nucleus again showed a time-dependence to the freezing process; however it did not fit a simple stochastic model, implying the presence of a spectrum of different nuclei (or nucleation sites) with different activities.

Given the evidence from the observations in this paper, and the laboratory studies cited above, we argue that a timedependent immersion freezing process is operating in these supercooled layer clouds.

\section{Rate of glaciation}

In this section we attempt to quantify the rate at which the ice phase grows at the expense of the liquid water. To do this, we estimate the vapour growth of an ice crystal of mass $m$ with time $t$ as:

$$
\frac{\mathrm{d} m}{\mathrm{~d} t}=4 \pi C \frac{S-1}{g(T, P)}
$$

where $S$ is the supersaturation with respect to ice and $g$ is a function of temperature and pressure as derived by Mason (1971). We have taken $S$ to be the value corresponding to saturation with respect to liquid water. The capacitance acts as an effective radius for the growing crystal, and we wish to relate this to the crystal sizes measured by the 2DS probe. To do this we note that for planar crystals such as those shown in figure $5, C / D \approx 0.25 \pm 0.05$ where $D$ is the maximum dimension of the crystal (see Westbrook et al. 2008, figure 11). Neglecting ventilation effects*, the rate of change of ice water content $\mathrm{dIWC} / \mathrm{d} t$ (balanced by a corresponding evaporation of droplets $-\mathrm{dLWC} / \mathrm{d} t$ ) is given by:

$$
\frac{\mathrm{dIWC}}{\mathrm{d} t} \approx \pi \frac{S-1}{g(T, P)} \int_{0}^{\infty} n(D) D \mathrm{~d} D
$$

Figure $5 \mathrm{~d}$ shows a time series of this quantity over a $25 \mathrm{~km}$ segment of a run near cloud top (within the supercooled layer), with observed values lying in the range 0.01$0.02 \mathrm{gm}^{-3} \mathrm{hr}^{-1}$. Note that this technique for computing $\mathrm{dIWC} / \mathrm{d} t$ does not require the assumption of a mass-size relationship.

Table 2 shows the run-averaged values of $\mathrm{dIWC} / \mathrm{d} t$ computed for the spectra from the four runs closest to cloud top, which were within or very close to the base of the supercooled layer. The mean value of this flux for the 4 runs is $0.015 \mathrm{gm}^{-3} \mathrm{hr}^{-1}$. The value from run-to-run varied by $\pm 40 \%$, presumably due to spatial inhomogeneities in the cloud. Taking this average as representative of the layer as a whole, we proceed to estimate the glaciation rate of the

\footnotetext{
* Sensitivity tests indicate that the error associated with neglecting ventilation is $\approx 10 \%$ in this case, based on the ventilation factors for planar crystals given in Ji and Wang (1999)
} 
Table 2. Estimated growth rates of ice crystals in supercooled layer, derived from aircraft size spectra. Values are averages over $100 \mathrm{~km}$ run. Standard error on mean dIWC/dt values for run are $\approx 0.001 \mathrm{gm}^{-3} \mathrm{hr}^{-1}$.

\begin{tabular}{ccc}
\hline Height $[\mathrm{m}]$ & $\mathrm{dIWC} / \mathrm{d} t\left[\mathrm{gm}^{-3} \mathrm{hr}^{-1}\right]$ & Run time [UTC] \\
\hline 3480 & 0.018 & 1216 \\
3465 & 0.007 & 1531 \\
3325 & 0.013 & 1505 \\
3175 & 0.021 & 1226 \\
\hline
\end{tabular}

supercooled layer. Since the supercooled layer is $\approx 220 \mathrm{~m}$ deep, we multiply $\mathrm{dIWC} / \mathrm{d} t$ by this depth to obtain the depletion rate of liquid water path: $3.3 \mathrm{gm}^{-2} \mathrm{hr}^{-1}$.

Comparing this derived depletion rate with the observed liquid water path of the cloud $\left(21 \mathrm{gm}^{-2}\right)$ it is clear that the glaciation of the layer is relatively slow - complete depletion of the liquid water path would take 6.4 hours at this rate.

In fact the cloud was observed to persist for $\sim 1$ day over Chilbolton. To explain this persistence beyond the glaciation time indicated above, we suggest that the slow cooling of the cloud layer as it emits infrared radiation to space is the most likely explanation. In simulations of the water budget in thin mixed-phase clouds Smith et al. (2009) found that radiative cooling of the layer was key to maintaining the liquid water content of the cloud. This idea is supported by soundings taken on the morning of 19th, showing that by the end of the observation period, cloud top had cooled by $\approx 1.5 \mathrm{~K}$, despite no observable change in the level of cloud top: this cooling will have led to condensation of water vapour. To estimate how much, we consider the instantaneous supply rate of condensate (eg Rauber and Tokay 1991):

$$
\frac{\mathrm{d} r_{v}}{\mathrm{~d} t}=-\left(\frac{c_{p}}{L_{v}}-\frac{r_{v}}{T}\right) \frac{\mathrm{d} T}{\mathrm{~d} t}
$$

neglecting any changes in cloud top pressure, where $r_{v}$ is the mixing ratio of water vapour in the (saturated) cloud layer, $c_{p}$ is the heat capacity of dry air, $L_{v}$ is the latent heat of vapourisation for water. Inserting the observed temperature, pressure $P$ and cooling rate $\frac{\mathrm{d} T}{\mathrm{~d} t}=1.5 \mathrm{Kday}^{-1}$ at cloud top based on the sounding data, one obtains a rate of change of liquid water content of $0.025 \mathrm{gm}^{-3} \mathrm{hr}^{-1}$. This is more than sufficient to offset the loss rate calculated from the observations.

\section{Conclusions}

Observations of a persistent supercooled layer cloud which steadily precipitated ice over many hours have been presented. We have used these observations to answer two key problems for the persistence of such clouds:

1. How does ice continually nucleate and precipitate from these clouds, without the available ice nuclei becoming depleted?

We have argued that the most plausible explanation for this observation given the magnitude of the observed flux of ice crystals precipitating from the layer is for ice nucleation to be a time-dependent process, and that in addition to the scarce numbers of efficient quasi-singular nuclei which are normally sampled by ice nucleus counters, there also exists a much larger number of less active nuclei which lead to droplets freezing slowly over time on timescales of many hours, or longer. An upper bound to this timescale can be provided by assuming every droplet contains an equally efficient nucleus or set of nuclei (the stochastic approximation). In this situtation the flux of ice particles each drop would have an average unfrozen lifetime of approximately 5 years (the concentration of liquid droplets $x$ the thickness of the supercooled layer $\div$ the observed flux of ice particles). Although extreme, this illustrates the potential of numerous, but slowly-activated ice nuclei to explain our observations.

2. How do the supercooled liquid droplets persist in spite of the net flux of water vapour to the growing ice crystals?

We show that in this example the flux of water vapour to the growing ice crystals is quite modest. In this example at least, the persistence of the liquid phase is explained simply by this relatively small flux, which can be offset by a small amount of radiative cooling.

One outstanding question is to what extent the fluxes of ice particles and water vapour in this case were 'typical' of this kind of cloud. More data are needed to answer this robustly. However, Field et al. (2004) sampled a somewhat similar supercooled layer cloud over Chilbolton (flight A819 in their paper). Again the crystals were oriented planar ice crystals; cloud top was $-15^{\circ} \mathrm{C}$. Using the in-situ data presented in their paper in an identical manner to the analysis above leads to an average flux of $150 \pm 36 \mathrm{~m}^{-2} \mathrm{~s}^{-1}$ crystals falling from the supercooled layer, while the glaciation rate is estimated as $0.01 \mathrm{gm}^{-3} \mathrm{~s}^{-1}$. These values are comparable in magnitude to the present case study, suggesting that our conclusions may be applicable beyond this particular example which we were fortunate enough to sample in detail with both aircraft and radar over a long period.

In this paper we have primarily focussed on the idea that the freezing process itself is time-dependent. A second possibility exists, which is that freezing is occuring via contact-nucleation from interstitial aerosol particles, which are gradually scavenged at random by the cloud droplets leading to freezing events which occur steadily over time. Since scavenging is a time-dependent process, and for large aerosols occurs rather slowly (Isaac and Douglas 1972), this may be another possible mechanism to explain our observations. Either way, our basic conclusion is unchanged: freezing events occur gradually over many hours, and this cannot be captured by short residence-time ice nucleus counters.

While the focus in this paper has been thin, weakly forced supercooled layers, there seems no reason why the same process should not be active in deeper frontal layer clouds where air ascends slowly within the warm conveyor belt. It is in these scenarios where the cooling rate is slow where time-dependence is likely to be most significant. This is in contrast to cumulus or wave clouds where the cooling is much more rapid, and any efficient (quasi-singular) nuclei present are likely to dominate the formation of ice because of the short time scales involved.

It is useful to consider the implications of the proposed time-dependent freezing process for numerical modelling of persistent supercooled clouds. For models with diagnostic ice nuclei (such as operational weather prediction and climate models) the number of ice nuclei available in a given grid box is never depleted by the nucleation and fallout processes of the ice particles. In a crude way, this lack of ice nucleus depletion could mimic the time-dependent freezing 
behaviour discussed in this paper. However since the concentrations of nuclei used in the parameterisations are based on quasi-singular ice nucleus counter measurements, this is not a physically consistent approach, and is unlikely to yield accurate nucleation rates.

For models with prognostic ice nuclei inclusion of the time-dependent behaviour becomes very important, otherwise the nuclei are rapidly depleted as found by Fridlind et al. (2012). Observational and laboratory techniques which can characterise both the temperatureand the time-dependence of freezing for candidate ice nuclei will be critical to properly parameterise this process.

\section{Acknowledgements}

We would like to thank Jonny Crosier, Keith Bower and FAAM for collection and processing of the in-situ data, along with Andrew Barrett and the staff at STFC Chilbolton for their help in collecting the radar observations. We acknowledge valuable discussions with Tom Choularton, Paul Connolly and Alan Blyth, and helpful comments from 2 anonymous reviewers which improved the quality of the manuscript. Thanks also to Paul Field for the aircraft data presented in Field et al. (2004). This study was part of the Natural Environment Research Council's APPRAISECLOUDS project, grant NE/EO11241.

\section{References}

Ansmann A et al. 2009. Evolution of the ice phase in tropical altocumulus: SAMUM lidar observations over Cape Verde $J$. Geophys. Res. 114 D17208

Baldwin MP and Vonnegut B 1982. Automatic apparatus for nucleation investigations. Rev. Sci. Instrum. 53 1911-1914

Barlow TW and Haymet ADJ et al. 1995. ALTA: an automated lag-time apparatus for studying nucleation of supercooled liquids. Rev. Sci. Inst. 66 2996-3007

Bergeron T 1935. On the physics of clouds and precipitation Proces Verbaux de l2̆018Association de Mtorologie Lisbon, Portugal, International Union of Geodesy and Geophysics, 156-178.

Bouniol D, Illingworth AJ and Hogan RJ, 2003. Deriving turbulent kinetic energy dissipation rate within clouds using ground based 94GHz radar. Proc. 31 AMS Conf. on Radar Meteorology, Seattle 192-196

Brenguier JL, 1991. Paramaterization of the condensation process: a theoretical approach. J. Atmos. Sci. 48 264-282

Broadley SL et al. 2012. Immersion mode heterogeneous ice nucleation by an illite rich powder representative of atmospheric mineral dust. Atmos. Chem. Phys. 12 287-307

Crosier J et al.. 2011. Observations of ice multiplications in a weakly convective cell embedded in supercooled mid-level stratus. Atmos. Chem. Phys. 11 257-273.

de Boer G et al.. 2011. Evidence of liquid-dependent ice nucleation in high-latitude stratiform clouds from surface remote sensors. Geophys. Res. Lett. 38 L01803.

DeMott PJ et al.. 2010. Predicting global atmospheric ice nuclei distribution and their impacts on climate. Proc. Nat. Acad. Sci. USA 107 11217-22.

Field PR. 2004: Simultaneous radar and aircraft observations of mixedphase cloud at the 100-m-scale. Q. J. R. Meteorol. Soc. $1301877-$ 1904.

Field PR. Heymsfield AJ, Bansemer A, 2006: Shattering and Particle Interarrival Times Measured by Optical Array Probes in Ice Clouds. J. Atmos. \& Ocean. Tech. 23 1357-1371.

Fridlind A et al. 2012. A FIRE-ACE/SHEBA case study of mixed-phase Arctic boundary-layer clouds: Entrainment rate limitations on rapid primary ice nucleation processes. J. Atmos. Sci. 69 365-389.

Goddard JWF, Eastment JD and Thurai M 1994. The Chilbolton Advanced Meteorological Radar: a tool for multidisciplinary atmospheric research. Electron. \& Comm. Eng. J. 6 77-86.
Hall MPM, Goddard JWF and Cherry SM 1984. Identification of hydrometeors and other targets by dual-polarization radar Radio Sci. 19 132-140

Heneghan et al. 2001. Liquid-to-Crystal Nucleation: Automated LagTime Apparatus to study supercooled liquids. J. Chem. Phys. 115 7599

Heneghan et al. 2002. Nucleation of Supercooled Water: new apparatus to determine stochastic behavior. J. Chem. Phys. 117 5319-5327.

Heneghan et al. 2002. Statistics of heterogeneous nucleation of supercooled water, and the effect of an added catalyst. Proc. Nat. Acad. Sci. 99 9631-9634

Heymsfield AJ and M Kajikawa 1987: An Improved Approach to Calculating Terminal Velocities of Plate-like Crystals and Graupel. J. Atmos. Sci. 44 1088-1099.

Hogan RJ et al. 2002. Properties of embedded convection in warmfrontal mixed-phase cloud from aircraft and polarimetric radar $Q . J$. R. Meteorol. Soc. 128 451-476

Hogan RJ et al. 2003. Characteristics of mixed-phase clouds: Part I: Lidar, radar and aircraft observations from CLARE'98. Q. J. R. Meteorol. Soc. 129 2089-2116.

Hogan RJ et al. 2004. Estimating the global distribution of supercooled liquid water clouds using spaceborne lidar. Geophys. Res. Lett. 32 L05106.

Hogan RJ et al. 2006. The retrieval of ice water content from radar reflectivity factor and temperature and its use in the evaluation of a mesoscale model J. Appl. Met. \& Clim. 45 301-317

Hogan RJ et al. 2012. Radar scattering from ice aggregates using the horizontally aligned oblate spheroid approximation. J. Appl. Met. \& Clim. 51 655-671.

Illingworth AJ et al. 2007. Cloudnet - continuous evaluation of cloud profiles in seven operational models using ground-based observations. Bull. Am. Meteorol. Soc. 88 883-898.

Isaac GA and RH Douglas 1972: Another "time-lag" in the activation of atmospheric ice nuclei. J. Appl. Meteorol. 11 490-493.

Ji W and PK Wang 1999: Ventilation coefficients for falling ice crystals in the atmosphere at low-intermediate Reynolds numbers. J. Atmos. Sci. 56 829-836.

Korolev A and Isaac G 2003. Phase transformation of mixed-phase clouds Q. J. R. Meteorol. Soc. 129 19-38

Korolev A and Isaac G 2005. Shattering during sampling by OAPs and HVPS J. Atmos. \& Ocean. Tech. 22 528-542

Korolev A and Field PR 2008.The Effect of Dynamics on Mixed-Phase Clouds: Theoretical Considerations J. Atmos. Sci. 65 66-86

Lawson RP et al. 2006. The 2D-S (stereo) probe: design and preliminary tests of a new airborne high-speed, high-resolution particle imaging probe. J. Atmos. \& Ocean. Tech. 23 1462-1477

Marsham J et al. 2006. Evaluation of a large-eddy model simulation of a mixed-phase altocumulus cloud using microwave radiometer, lidar and Doppler radar data. Q. J. R. Meteorol. Soc. 132 1693-1715.

Mason BJ 1971. The physics of clouds Oxford University Press, second edition.

Murray BJ et al. 2011. Heterogeneous freezing of water droplets containing kaolinite particles. Atmos. Chem. Phys. 11 4191-4207.

Nicholls S and Leighton J 1986. An observational study of the structure of stratiform cloud sheets: Part I. Structure. Q. J. R. Meteorol. Soc. 112 431-460

Niedermeir D et al. 2011. Heterogeneous ice nucleation: exploring the transition from stochastic to singular freezing behaviour. Atmos. Chem. Phys. 11 8767-8775.

Rauber RM and Tokay A 1991. An explanation for the existence of supercooled liquid water at the top of cold clouds. J. Atmos. Sci. 48 1005-1023.

Pruppacher HR and Klett JD 1997. Microphysics of clouds and precipitation, Second edition, Kluwer, London.

Shupe MD et al. 2011. Clouds at arctic atmospheric observatories. Part I: occurrence and macrophysical properties. J. Appl. Meteorol. \& Clim. 50 626-643

Smith AJ et al. 2009. Processes that generate and deplete liquid water and snow in thin midlevel mixed-phase clouds. J. Geophys. Res. 114 D12203

Stevens B et al. 2002. Entrainment in stratocumulus-topped mixed layers. Q. J. R. Meteorol. Soc. 128 2663-2690 
Vali G and Stansbury EJ 1966. Time-dependent characteristics of the heterogeneous nucleation of ice. Canadian J. Phys. 44 477-502

Vali G 1994. Freezing rate due to heterogeneous nucleation. J. Atmos. Sci. 51 1843-1856

Vali G 2008. Repeatability and randomness in heterogeneous freezing nucelation. Atmos. Chem. Phys. 8 5017-5031

Vonnegut B 1948. Variation with temperature of the nucleation rate of supercooled liquid tin and water drops. J. Colloid Sci. 3 563-569.

Vonnegut B 1949. Nucleation of supercooled water clouds by silver iodide smokes. Chem. Rev. 44 277-289.

Vonnegut B. and Baldwin MP, 1984. Repeated Nucleation of a Supercooled Water Sample that Contains Silver Iodide Particles. J. Appl. Meteorol. 23 486-490

Westbrook CD, Hogan RJ and Illingworth AJ 2008. The capacitance of pristine ice crystals and aggregate snowflakes. J. Atmos. Sci. 65 206209.

Westbrook CD and Davies OT 2010. Observations of glaciating holepunch cloud. Weather 65 176-180.

Westbrook CD et al. 2010a. Doppler lidar measurements of oriented planar ice crystals falling from supercooled and glaciated layer clouds. Q. J. R. Meteorol. Soc. 136 260-276.

Westbrook CD et al. 2010b. Estimates of drizzle drop size and precipitation rate using two-colour lidar measurements. Atmos. Meas. Tech. 3 671-681.

Westbrook CD and Illingworth AJ 2011. Evidence that ice forms primarily in supercooled liquid clouds at temperatures $>-27^{\circ} \mathrm{C}$. Geophys. Res. Lett. 65 176-180.

Wilson PW and Haymet ADJ 2009. Effect of solutes on the heterogeneous nucleation temperature of supercooled water: an experimental determination. Phys. Chem. Chem. Phys. 11 2679-2682

Zhang D, Wang Z and Liu D 2010. A global view of mid-level liquid-layer topped stratiform cloud distribution and phase partition from CALIPSO and CloudSat measurements J. Geophys. Res. 115 D00H13 